\title{
Electrochemically active Ir NPs on graphene for OER in acidic aqueous electrolyte investigated by in situ and ex situ spectroscopies
}

\author{
J. J. Velasco-Vélez ${ }^{1,2, *}$, T. E. Jones ${ }^{2}$, V. Streibel ${ }^{2}$, M. Hävecker ${ }^{1}$, C.-H. Chuang ${ }^{3}$, L. Frevel ${ }^{1}$, M.

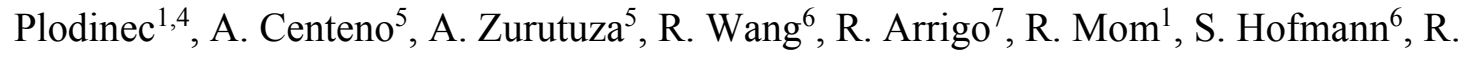 \\ Schlögl ${ }^{1,2}$ and A. Knop-Gericke ${ }^{2}$ \\ *Corresponding author: velasco@fhi-berlin.mpg.der
}

\author{
${ }^{1}$ Department of Heterogeneous Reactions, Max Planck Institute for Chemical Energy Conversion, Mülheim an der \\ Ruhr 45470, Germany \\ ${ }^{2}$ Department of Inorganic Chemistry, Fritz-Haber-Institut der Max-Planck-Gesellschaft, Berlin 14195, Germany \\ ${ }^{4}$ Rudjer Boskovic Institute, Bijenicka 54, HR-10000 Zagreb, Croatia \\ ${ }^{5}$ Graphenea, San Sebastian 20018, Spain \\ ${ }^{6}$ Department of Engineering, University of Cambridge, Cambridge CB3 0FA, United Kingdom \\ ${ }^{7}$ Diamond Light Source Ltd, Harwell Science \& Innovation Campus, Didcot, Oxfordshire OX 11 0DE, UK
}

\begin{abstract}
An electrode for the oxygen evolution reaction based on a conductive bi-layered free standing graphene support functionalized with iridium nanoparticles was fabricated and characterized by means of potentiometric and advanced X-ray spectroscopic techniques. It was found that the electrocatalytic activity of iridium nanoparticles is associated to the formation of Ir $5 d$ electron holes. Strong Ir $5 d$ and O $2 p$ hybridization, however, leads to a concomitant increase $\mathrm{O} 2 \mathrm{p}$ hole character, making oxygen electron deficient and susceptible to nucleophilic attack by water. Consequently, more efficient electrocatalysts can be synthesized by increasing the number of electron-holes shared between the metal $\mathrm{d}$ and oxygen $2 \mathrm{p}$.
\end{abstract}

Keywords: Photoelectron spectroscopy, OER, Ir nanoparticles, graphene membrane, aqueous electrolyte.

\section{Introduction}

The treatment of greenhouse gases and the mitigation of their effects is one of the most important global challenges humanity is now facing [1]. These challenges include the effects of global warming on the climate and their consequences for humans [2], plants, and animals [3], as well as the negative health effects of toxic gases and suspended nanoparticles [4,5]. This issue has to be solved while still providing enough energy to feed a growing population (more than 7 billion) and to operate an infrastructure, which requires bigger and more efficient transportation networks [6]. Renewables (including wind, solar and tidal power) enable opportunities for a large, continuous, and clean energy supply [7]. However, one of the biggest challenges for an economically viable implementation of renewable energy technologies in the current energy infrastructure is caused by the intermittent nature of these energetic resources, which does not match the demand. This mismatch requires strategies to store excess energy for later use. Electrochemical energy conversion and storage plays a crucial role in the overall solution of the global energy challenges [8]. In particular, hydrogen obtained via electrochemical oxidation of water has the potential to replace fossil fuels as a storable and clean fuel [9]; however, this technology requires further development before it can be applied on a large scale [7]. In fact, because of the slow kinetics of the anodic oxygen evolution reaction (OER) [10], it is necessary to apply potentials well beyond the thermodynamically required potential of $1.23 \mathrm{~V}$ (vs. SHE) to split 
water molecules into their principal components (hydrogen and oxygen). For example, to achieve current densities of at least $10 \mathrm{~mA} / \mathrm{cm}^{2}$ over-potentials of hundreds of millivolts above the OER equilibrium potential have to be applied, with a drastic reduction of the process efficiency $[11,12]$.

Due to their low overpotential and high stability in acidic media iridium-based oxides have been shown to be good candidates for the electrocatalytic oxidation of water [13, 14]. Unfortunately, iridium is among the scarcest materials in the earth's crust. Thus, optimized strategies are required for its usage; e.g. by increasing the surface to bulk ratio of the iridium particles [15]. An electronic effect exerted by the active Ir metal species causes the enhanced activity observed, however a detailed chemical speciation is still elusive and is even contradictory in literature in many cases, which requires further investigation to optimize synthesis approaches. Well dispersed nanoparticles (NPs) are usually not electrically connected between each other requiring a different strategy to apply the required potential to flow the electrical current necessary to run the reaction. This limitation can be circumvented by using a conductive support material, which drives the current to the catalytic active centers. In this way, the support layer provides electrical contact for the different catalyst NPs yielding high activity and stability under OER conditions, comparable to bulk materials [16]. Graphene was selected as a possible candidate substrate due to its high mechanical strength and flexibility, exceptional thermal and electrical conductivity, and chemical stability under harsh reaction conditions [17-20]. It is well known that defect-free graphene layer is not electro/chemically active [21] and requires functionalization with heteroatoms to manifest chemical reactivity making it as an ideal substrate for electrocatalytic investigations due to its low contribution to the overall reaction rates, allowing the correlation of the catalytic activity to the supported metal.

Photoelectron spectroscopy (PES) is a powerful surface sensitive technique, which provides information about the electronic structure of the core-levels in a non-destructive way. This technique has been applied to a wide range of systems in order to elucidate their chemical composition. The implementation of this technique under reaction conditions is however complicated by the so called "pressure gap" [22] between the high pressure required for realistic reaction conditions and the ultra-high vacuum (UHV) needed in conventional PES chambers for their operation. Recently, holey grids made of Si nitride were combined with photoelectrons transparent bi-layers graphene (BLG) to form windows, which separate the liquid environment from the evacuated (UHV) PES chamber [23, 24]. With this approach it was possible to investigate electrochemical electrified interfaces in the presence of liquid electrolytes and gases [22] under reaction conditions. By taking advantage of this approach, in situ X-ray photoelectron spectroscopy (XPS) was accomplished, allowing the direct correlation between the electronic structure of $\mathrm{IrO}_{\mathrm{x}}$ (active sites) and its electrocatalytic activity during OER.

In this work, we investigate the variation in the electronic structure of Ir NPs on conductive bi-layers of graphene (BLG) as consequence of applied potential under OER in acidic conditions. 
We combine in situ with ex situ $\mathrm{X}$-ray photoelectron

spectroscopy (PES) and X-ray absorption nearedge structure (XANES) to unveil still undisclosed electronic structural information on the $\mathrm{IrO}_{\mathrm{x}}$ active in OER. In particular, valuable information of the occupied (Ir 4f) and partially occupied (Ir 5d, O $2 p$ ) orbitals is obtained with these techniques. We show that the formation of electronholes in the hybridized $\mathrm{O}$ $2 \mathrm{p} / \mathrm{Ir} 5 \mathrm{~d}$ levels is linked to the electrochemical activity shown by iridium oxide. These holes lead to the formation of electron deficient oxygen species, which are the likely centers in the formation

of molecular oxygen due to nucleophilic attack by $\mathrm{OH}$ or $\mathrm{H}_{2} \mathrm{O}$. Furthermore, we report the structural descriptor of the electrocatalytic activity as a consequence of $\operatorname{Ir} 5 \mathrm{~d}$ and $\mathrm{O} 2 \mathrm{p}$ hybridization and shared electron-holes and provide guidance for the synthesis of improved electrode materials for OER.

\section{Experimental}

Beamlines: In situ synchrotron radiation based experiments were performed at the ISISS beamline of BESSY II in Berlin (Germany). In this facility, the photons are sourced from a bending magnet (D41) and a plane grating monochromator (PGM) yielding an energy range from $80 \mathrm{eV}$ to $2000 \mathrm{eV}$ (soft X-ray range), a flux of $6 \times 10^{10}$ photons/s with $0.1 \mathrm{~A}$ ring current using a $111 \mu \mathrm{m}$ slit and a $80 \mu \mathrm{m}$ x $200 \mu \mathrm{m}$ beamspot size. The in situ measurements were accomplished in the ambient pressure X-ray photoelectron spectrometer (AP-XPS) end-station of the ISISS beamline [25]. 
Hard X-ray absorption measurements at the Ir $\mathrm{L}_{3}$-edge were performed at the beamline BL17C1 [26] of the National Synchrotron Radiation Research Center (NSRRC) in Hsinchu (Taiwan). The photons are sourced from a 25 poles wiggler (W20) with $20 \mathrm{~cm}$ period length and a focus spot size of $2 \mathrm{~mm} \times 6 \mathrm{~mm}$. The excitation energy ranges from $4.8 \mathrm{keV}$ up to $14.2 \mathrm{keV}$. The signal was collected in transmission mode for the powder samples and in fluorescence yield mode for the foil, using an ionization chamber detector.

Electrode preparation: Graphene was grown by catalytic chemical vapor deposition (CVD) on a $20 \mu \mathrm{m}$ thick $\mathrm{Cu}$ foil (Alfa Aesar $99.8 \%$ ) using $\mathrm{CH}_{4}$ (diluted in $\mathrm{Ar}$ and $\mathrm{H}_{2}$ ) served as the precursor at $1000{ }^{\circ} \mathrm{C}$ in an Aixtron BM Pro (4 inch) reactor. This procedure yielded a continuous polycrystalline film with a grain size in the range of $\sim 20 \mu \mathrm{m}$, which was confirmed by scanning electron microscopy. The graphene layer was fixed to $500 \mathrm{~nm}$ of Poly(methyl methacrylate) PMMA (4 wt.\% in anisole, $950 \mathrm{k}$ molecular weight) deposited by spin coating. After that, the $\mathrm{Cu} / \mathrm{graphene} / \mathrm{PMMA}$ composite was left floating on a $50 \mathrm{mM}$ aqueous solution of $\left(\mathrm{NH}_{4}\right)_{2} \mathrm{~S}_{2} \mathrm{O}_{8}$ in order to detach the copper support. Then the graphene/PMMA layer was floated in deionized water (DI-water) and transferred onto another graphene/copper foil and dried at $50{ }^{\circ} \mathrm{C}$ for 5 minutes. The resulting sample was floated again on the $100 \mathrm{mM}\left(\mathrm{NH}_{4}\right)_{2} \mathrm{~S}_{2} \mathrm{O}_{8}$ solution, to remove the copper foil, and rinsed in DI-water. The PMMA/BLG layer was transferred onto a micro-structured Norcada ${ }^{\circledR} \mathrm{Si}_{3} \mathrm{~N}_{4}$ TEM grid with a holey area of $200 \mu \mathrm{m}$ x $200 \mu \mathrm{m}$ with $500 \mathrm{~nm}$ holes and a $1.2 \mu \mathrm{m}$ pitch distance between them. Finally the PMMA was removed by dissolution in acetone and rinsing in isopropanol (IPA). The adherence between the BLG and the substrate is due to van der Waals interaction ensuring stability for the electrodes. It produces a continuous film that can be used as an electrode in aqueous environments and electrocatalytic applications, among others $[21,27]$. After the graphene had been transferred to the support, Ir nanoparticles were sputtered onto the surface with a Cressington 208HR sputter coater. The target was Ir 99.99\% purity grade (Elektronen-Optik-Service GmbH, Dortmund, Germany), the Ar pressure 0.1 mbar, the current $40 \mathrm{~mA}$, and the sputtering duration 5 seconds. This deposition provides homogeneously distributed Ir NPs on the surface of the graphene, as shown in the TEM measurements (Figure 1A). A detailed analysis of these measurements revealed a uniform distribution of $\sim 2 \mathrm{~nm}$ NPs covering $22 \%$ of the surface on average (Figure 1A). These particles are composed of metallic Ir which is confirmed by electron energy loss spectroscopy (EELS), where the measured $\operatorname{Ir} \mathrm{O}_{2,3}$ and $\operatorname{Ir} \mathrm{N}_{6,7}$ edges correspond to the metallic Iridium spectra [28] (see Figure 1D). A closer inspection to the morphology shows that the particles are well anchored to the graphene support and exhibit $\operatorname{Ir}^{0}(111)$ face centred cubic (fcc) crystal structure with a lattice plane distance of $0.23 \mathrm{~nm}$, which was confirmed by the Fast Fourier Transformation (FFT) of HRTEM image and is in good agreement with the EELS measurements. The excellent anchorage of the iridium NPs is proved by the ex-situ TEM characterization after the OER (Figure C).

The transmission electron microscopy (TEM) and electron energy loss spectroscopy (EELS) analysis were performed in a Philips CM200 FEG TEM equipped with a GIF Quantum 
energy filter and Tridiem camera. The EELS spectra were acquired in TEM mode with 1 second acquisition time and energy dispersion of $0.1 \mathrm{eV} /$ channel.

In situ electrochemical

cell: The liquid flow cell was operated inside the main chamber of the AP-XPS endstation of the ISISS beamline [25] at a background pressure of $\sim 10^{-7}$ mbar while aqueous solutions circulated on the back side of the free standing graphene membrane described above, which is used as the working electrode. The continuous flow of liquid was assured by a syringe pump 260D Teledyne Isco (Lincoln, USA). The main body of the electrochemical cell is made of polyether ether ketone (PEEK), which is an exceptional electrical insulator and chemically inert. The sealing was assured with several Kalrez O-rings which have good chemical stability. The cell contains two additional electrodes, the counter(platinum) and referenceelectrode ( $\mathrm{Ag} / \mathrm{AgCl}$ DRIREF-

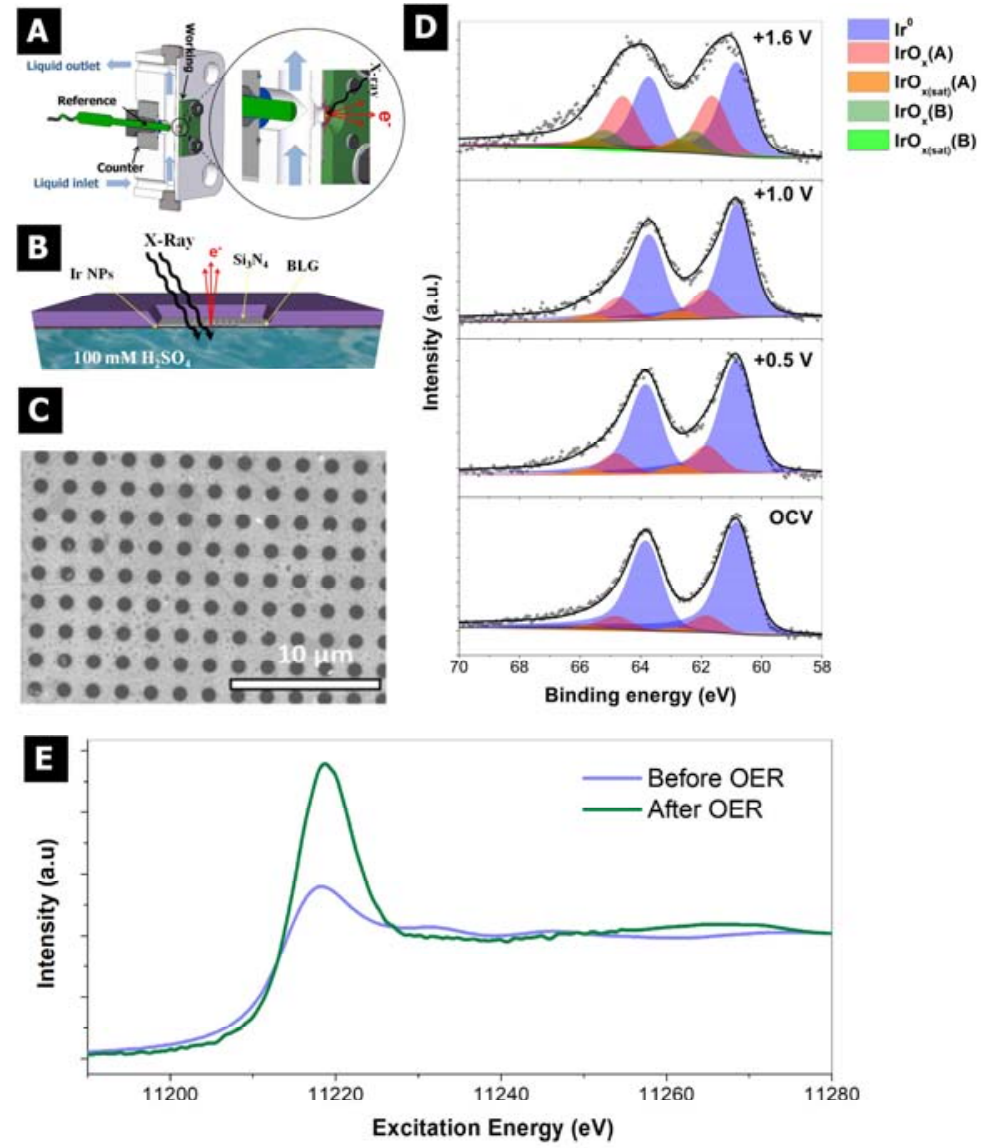

Figure 2: (A) Schematic drawing of the in situ electrochemical cell. (B) Detection scheme. (C) SEM image of the holey $\mathrm{SiN}_{\mathrm{x}}$ structure covered by free standing BLG. (D) In situ characterization of the Ir $4 \mathrm{f}$ electronic structure under different applied potentials in presence of $0.1 \mathrm{M} \mathrm{H}_{2} \mathrm{SO}_{4}$. (E) Ir L-edge before and after the oxygen evolution reaction of a $20 \mathrm{~nm}$ sputtered Ir thin film

2SH, World Precision Instruments, USA). A cross-section of the cell is depicted in Figure 2A. A more detailed description was previously reported [24]. Figure $2 \mathrm{~B}$ shows the detection scheme through the membrane which requires photoelectrons of at least $500 \mathrm{eV}$ to "escape" through the free standing graphene and reach the vacuum side where the analyzer is placed. The free-standing graphene membrane is used as an electrode, as a support for the Ir NPs, and as a photoelectron transparent window preventing the liquid electrolyte from leaking into the chamber. A scanning electron microscope (SEM) image of the $\mathrm{SiN}_{\mathrm{x}}$ grid coated with a free standing BLG and decorated with Ir NPs is shown in Figure 2C. With this approach, it was possible to investigate electrochemical interfaces in presence of liquids. Herein, we use it to investigate the electronic structure of iridium in presence of an aqueous acidic electrolyte under different potentials. This 
cell was operated in the ISISS beamline of the synchrotron facility BESSY II (Berlin, Germany) [25] establishing a pressure in the main chamber of $\sim 10^{-7}$ mbar while aqueous electrolyte $(0.1 \mathrm{M}$ $\left.\mathrm{H}_{2} \mathrm{SO}_{4}\right)$ is flowed $(1 \mathrm{ml} / \mathrm{min})$ on the back side of the membrane, which removes the bubbles formed during the OER and by water radiolysis. The Ir $4 \mathrm{f}$ spectra were collected with a kinetic energy of the photoelectrons of $600 \mathrm{eV}$ (excitation energy of $660 \mathrm{eV}$ ) at different potentials. At open circuit potential (OCP) the Ir $4 \mathrm{f}$ peak consists of two main peaks ascribed to the spin orbit split $\operatorname{Ir} 4 \mathrm{f} 7 / 2$ and $\operatorname{Ir} 4 \mathrm{f} 5 / 2$ stats.

Electrolyte preparation: The electrolyte was prepared by diluting $9.8 \mathrm{~g}$ of $\mathrm{H}_{2} \mathrm{SO}_{4}$ (purity $98 \%$, Alfa Aesar, Massachusetts, USA) in 1 liter of Milli-Q water (18.2 M $\Omega$ ) at room temperature (RT), $25^{\circ} \mathrm{C}$. The electrolyte was continuously saturated by bubbling pure $\mathrm{N}_{2}$ gas, which minimizes the presence of other dissolved gases in the electrolyte. The electrolyte is acidic with a $\mathrm{pH}$ equal to 1 .

Potentiostat: Potentiometric control was assured with a Biologic SP-300 (SeyssinetPariset, France) allowing different potentiometric and amperometric controls.

Reference samples: Commercially available iridium powders were purchased from Sigma-Aldrich (99.9\% trace metals basis) and AlfaAesar (Premion, 99.99\% trace metals basis). In addition, Ir foil was purchased from Mateck (99.99\% metals basis). The AlfaAesar powder was used as received and the SigmaAldrich powder was washed in Milli-Q water and calcinated at 800 ${ }^{\circ} \mathrm{C}$ in $\mathrm{O}_{2}$ for 50 hours. The AlfaAesar powder is X-ray amorphous $\left(\mathrm{IrO}_{\mathrm{x}}\right)$ while the calcinated sample of SigmaAldrich exhibits the rutile-type structure $\left(\mathrm{IrO}_{2}\right)$. More details of the sample preparation/characterization can be found elsewhere [29]. The Ir foil was subjected to several cycles of sputtering in $\mathrm{Ar}^{+}$atmosphere and annealing in $\mathrm{H}_{2}$ atmosphere and shows a purely metallic phase.

DFT calculations: All calculations were performed using the Quantum ESPRESSO package [30] using the Perdew, Burke, and Ernzerhof (PBE) exchange and correlation potential [31] with ultrasoft pseudo potentials from the PSLibrary [32]. A kinetic energy (charge density) cutoff of $30 \mathrm{Ry}$ (300 Ry) was used. The $\mathrm{IrO}_{\mathrm{x}} \mathrm{H}_{\mathrm{y}}$ surface was modeled as a five-layer (110) slab separated from its periodic image by ca. $15 \AA$ of vacuum. Both surfaces of the slab were allowed to relax while the central layer was held fixed at its bulk value. The Brillouin zone was sample with a $(12 \times 6 \times 1)$ k-point mesh using Marzari-Vanderbilt smearing [33] with a parameter of 0.01 Ry. Integrated charges were determined by a Löwdin population analysis.

\section{Results and Discussion}

The electrocatalytic performance of the graphene electrode described in the experimental section was investigated by means of linear sweep voltammetry (LSV) and cyclic voltammetry $(\mathrm{CV})$. Figure 1B shows the cyclic voltammogram (CV) of this assembly performed at room temperature with a scan rate of $20 \mathrm{mV} / \mathrm{s}$ in $0.1 \mathrm{M} \mathrm{H}_{2} \mathrm{SO}_{4}$ versus a $\mathrm{Ag} / \mathrm{AgCl}$ reference electrode and a Pt counter electrode. The CV shows two oxidation waves, I and II, and two reduction waves,

IV and V, in addition to III, which is ascribed to the oxidation of water. It is broadly accepted that $\mathrm{I} / \mathrm{V}$ and II/IV are redox couples [34]. In addition, the LSV of pristine graphene was compared to a 
graphene electrode decorated with $\sim 2 \mathrm{~nm}$ Ir NPs, which cover $\sim 20 \%$ of the electrode's surface (inset Figure 1B). The electrochemical characterization clearly indicates that the addition of Ir NPs decreases the OER overpotential significantly and increases the current density during OER. As expected, the electrode decorated with Ir NPs is more active, based on the onset potential and current density, than the pristine graphene electrode, proving the correct performance of the experimental methodology used in this work. Notwithstanding the increase in electrocatalytic performance of the graphene electrode when it is decorated with Ir NPs, the nature of the active sites under reaction conditions are still not completely understood. After the OER the electrode was investigated by ex situ transmission electron microscopy (TEM) and electron energy loss spectroscopy (EELS) techniques. Figures 1C shows the TEM images of the sputtered particles on graphene after the OER, which are homogenous distributed particles on the surface of the graphene with coverage factor of around $20 \%$ and particles size of $2 \mathrm{~nm}$ in average. The fast Fourier transformation (FFT) pattern proves the existence of reduced iridium particles (induced by the beam) and the two additional rings ascribed to the existence of a non-well defined crystal structure due to the presence of non-stoichiometric iridium oxide $\left(\operatorname{Ir}_{\mathrm{x}} \mathrm{O}_{\mathrm{y}}\right)$ or/and defects in the lattice. At higher magnification it was found that the iridium nanoparticles are reduced to Ir metallic under vacuum condition in presence of the beam irradiation. It is a well-known issue related to the existence of a non-stoichiometric iridium oxide $\left(\operatorname{Ir}_{\mathrm{x}} \mathrm{O}_{\mathrm{y}}\right)$ giving $\operatorname{Ir}^{0}(111)$ cubic structure with a lattice plane distance of $0.23 \mathrm{~nm}$ as product of the reduction induced by the beam. Furthermore, EELS performed before and after the OER, just as prepared Ir NPs and after OER, showing that the Ir NPs are metallic after the deposition by sputtering (as shows in Figure 1D). On the other hand, after the OER, the particles present substantial changes in the electronic structure mostly ascribed to its oxidation state. The EELS spectrum presents a peak at around $51.5 \mathrm{eV}$ and a shoulder at $56.5 \mathrm{eV}$, as well as Ir $\mathrm{N}_{6-7}$ edges at $62 \mathrm{eV}$ and $65 \mathrm{eV}$ for the $\mathrm{N}_{7}$ and $\mathrm{N}_{6}$ transitions respectively, which are ascribed to $\mathrm{IrO}_{\mathrm{x}}$ [35]. The differences in the peak height between $\mathrm{Ir}$ as deposited and after OER indicate a change in the electronic structure due to the NPs oxidation. It is generally accepted that the active sites are hydrated Ir-oxohydroxides formed during the OER [36], however the molecular level description of the species responsible for the high catalytic activity is still debated. The results of the in situ characterization of this assembly are shown in Figure 2D. The Ir 4f spectra were recorded by detecting electrons with a kinetic energy of $600 \mathrm{eV}$ at different potentials. At open circuit potential (OCP), the Ir $4 \mathrm{f}$ peak consists of two main peaks ascribed to the spin orbit splitting in Ir 4f7/2 and Ir 4f5/2, respectively. Reference spectra from known Ir oxides are used to fingerprint features in the spectra recorded in situ. For this purpose, three samples were selected: metallic Ir foil, rutile powder, and amorphous powder, as described in the experimental section. Figure $3 \mathrm{~A}$ shows the $\mathrm{Ir} 4 \mathrm{f}$ spectra of metallic $\mathrm{Ir}$, rutile $\mathrm{IrO}_{2}$ and amorphous $\mathrm{IrO}_{\mathrm{x}}$. The metallic main peak (blue) has a binding energy of $60.8 \mathrm{eV}$ and $\mathrm{IrO}_{2}$ (red) is shifted to higher binding energies $(61.7 \mathrm{eV})$. It is noticeable that for the case of $\mathrm{IrO}_{\mathrm{x}}$ (green) the spectrum is broader than for $\mathrm{IrO}_{2}$ indicating the existence of another oxidation state at higher binding energy [29]. In addition, the comparison of these measurements with the ex situ Ir L $3-$ 
edge indicate the formation of more $5 \mathrm{~d}$ electron holes as the consequence of the transition from occupied Ir $2 \mathrm{p}$ to unoccupied Ir $5 \mathrm{~d}$ as shown in figure $2 \mathrm{E}$.

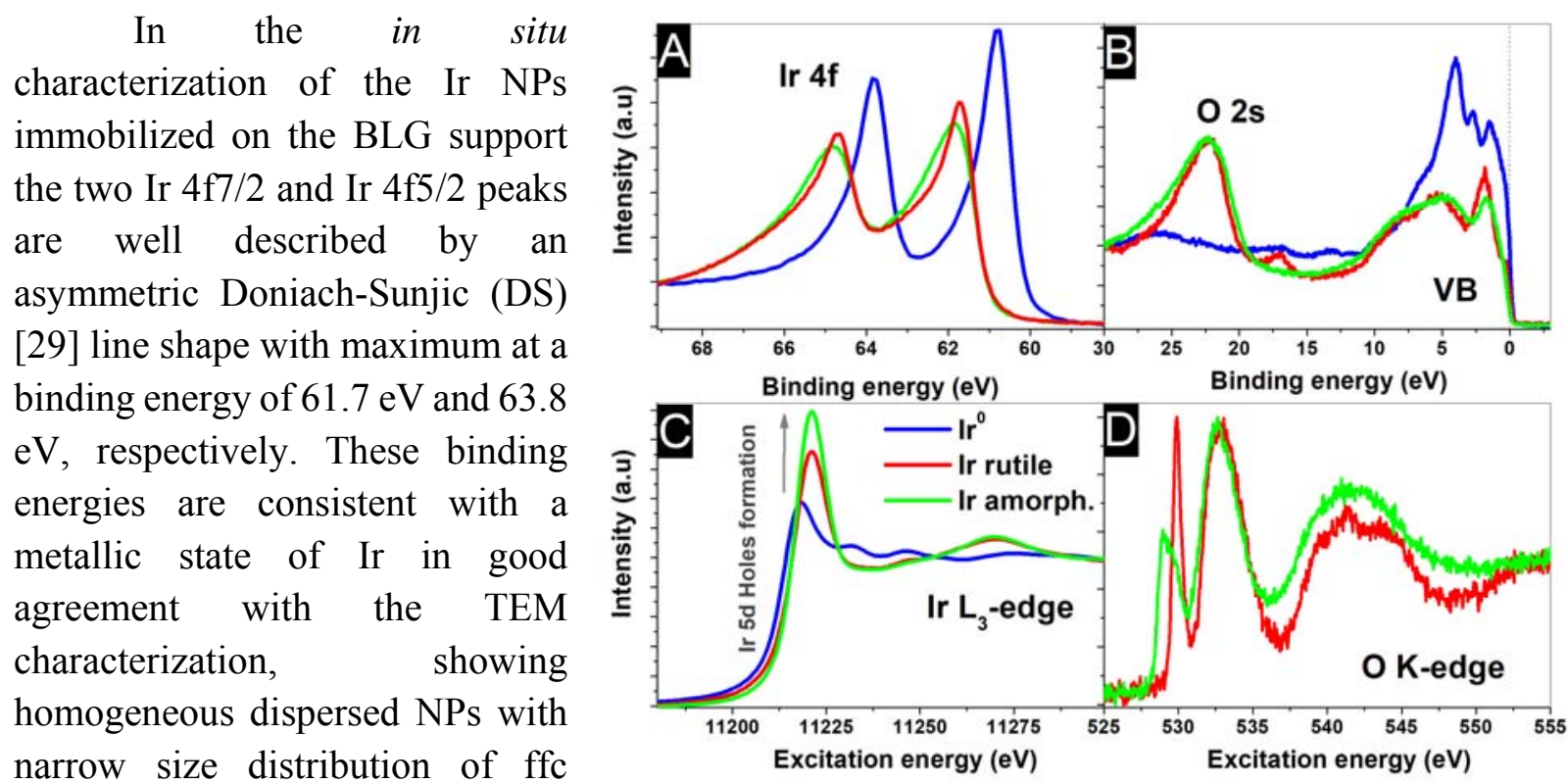
crystals with a $\operatorname{Ir}^{0}$ (111) lattice plane at a distance of $0.23 \mathrm{~nm}$. Two additional components fitted with a

Figure 3: Ex situ characterization of the fingerprint samples $\operatorname{Ir}^{0}, \mathrm{Ir}$ rutile and Ir amorphous: (A) Ir 4f, (B) VB and O 2s (C) Ir L-edge and (D) O K-edge.

DS line shape appear at a binding energies of $61.8 \mathrm{eV}$ and $64.8 \mathrm{eV}$, which, together with the shakeup satellites at $1 \mathrm{eV}$ above the main line, can be ascribed to the formation of iridium oxide $\left(\operatorname{IrO}_{\mathrm{x}}(\mathrm{A})\right.$, like $\mathrm{IrO}_{2}$ rutile shape). Upon anodic polarization of the electrode at potentials of $+0.5 \mathrm{~V}$ and +1.0 $\mathrm{V}$ the contribution of the $\mathrm{IrO}_{\mathrm{x}}(\mathrm{A})$ species increases. Under OER conditions $(+1.6 \mathrm{~V})$, the spectrum evolves into a broader peak shape, which is fitted with two additional DS peaks at $62.3 \mathrm{eV}$ and $65.3 \mathrm{eV}$ and associated satellites $1 \mathrm{eV}$ above the main peaks ascribed to the formation of an additional oxidation state $\left(\mathrm{IrO}_{\mathrm{x}}(\mathrm{B})\right.$, like amorphous $\mathrm{IrO}_{\mathrm{x}}$ oxide as shown below). Such a broad $\mathrm{Ir}$ 4f line shape has been reported under reaction conditions using a proton exchange membrane (PEM) [37, 38], which is also present under aqueous electrolyte conditions as it was shown in the in situ experiments in this work. The authors linked the higher binding energies of the $\mathrm{Ir} 4 \mathrm{f}$ level under OER conditions to the formation of an active mixed valence iridium oxide phase. The experiments showed that metallic iridium NPs are transformed into amorphous oxo-hydroxide with increasing potential. Meanwhile, Pfeifer and co-workers have provided for the first time the evidence of the formation of an electron deficient intermediated oxygen species, associated to the active oxide phase [39], providing not only new mechanistic insights into the OER but also confirming further APXPS as a unique tool in surface/interface science and catalysis. Therein, the electron deficient oxygen species were suggested to be susceptible to nucleophilic attack from $\mathrm{OH}$ groups or water yielding intermediated hydroperoxo groups, which finally decompose into molecular oxygen. These species are strongly correlated with the existence of an Ir mixed valence state, but unambiguous speciation is still challenging. This complication arises from the fact that 
the occupancy of the Ir $5 \mathrm{~d}$ orbitals in the oxide is still unknown whilst its knowledge is of paramount importance as it is directly involved in the hybridization with the $\mathrm{O} 2 \mathrm{p}$ orbitals of the oxygen ligands determines their chemical nature and stability.

To help the assignment of the chemical state of the OER active Ir oxide phase, we complement core level Ir 4f PES with valence band (VB) PES and XANES at the Ir L-edge and $\mathrm{O}$ Kedge. The variation in the oxidation state has also a severe effect in the in the VB spectra (Figure 3B) were the density of states (DOS) close to the Fermi edge are diminished following the shift to higher BEs observed in the Ir $4 \mathrm{f}$ spectra, which is linked to the occupied $\mathrm{O} 2 \mathrm{p}$ and Ir $5 \mathrm{~d}$ orbitals. Figure 3C shows the Ir L3-edge which corresponds to the electron transition from the occupied $2 \mathrm{p}_{3 / 2}$ level to the partially occupied Ir $5 \mathrm{~d}$ $\left(\pi^{*}\right)$ and $\operatorname{Ir} 6 \mathrm{sp}\left(\sigma^{*}\right)$ orbitals. The orbital splitting into $t_{2 g}$ and $e_{g}$ states cannot be resolved in these spectra due the large lifetime broadening [40]. It is obvious that the increase in the main peak intensity of the $\mathrm{Ir}_{3} \mathrm{~L}_{3}$ spectra follows the trend $\mathrm{IrO}_{\mathrm{x}}>\mathrm{IrO}_{2}>\mathrm{Ir}^{0}$ revealing that the number of unoccupied states in the $5 \mathrm{~d}$ band is

Increase in the oxidation state
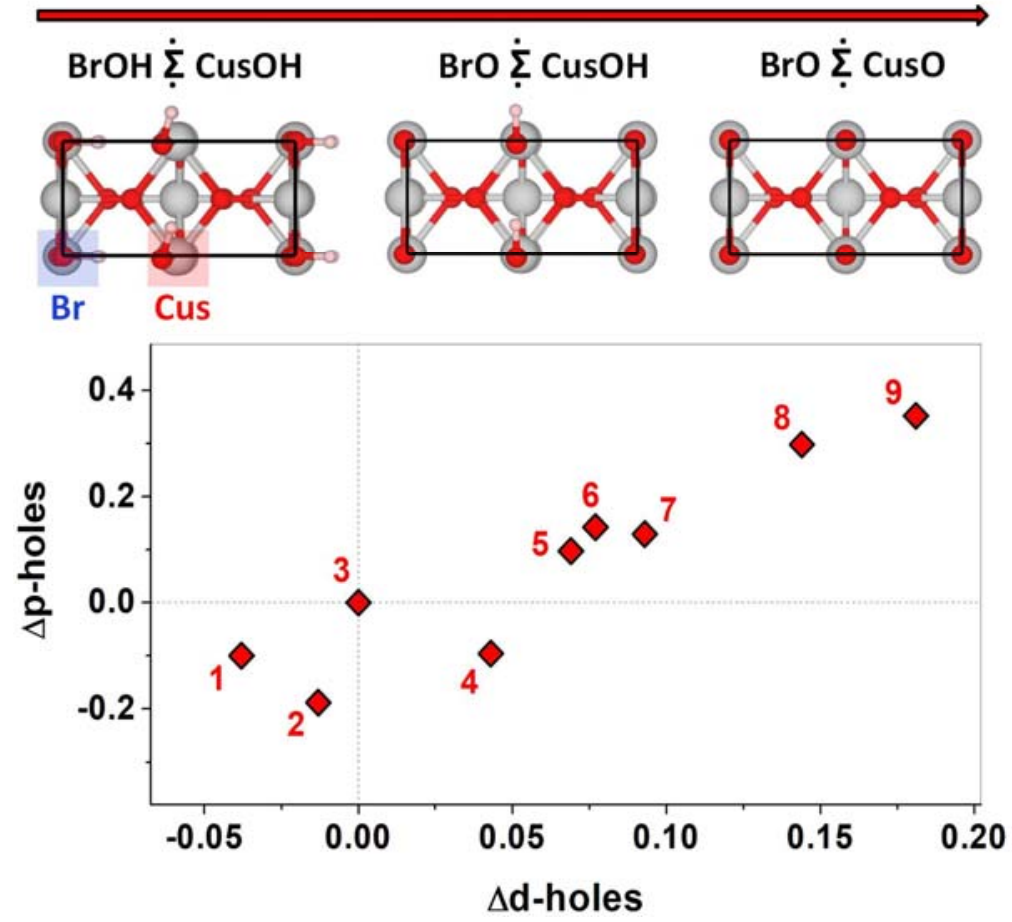

Figure 4: Change in $\mathrm{O} 2 \mathrm{p}$ hole character (with respect to $\mathrm{O}$ in bulk $\mathrm{IrO}_{2}$ ) on as a function of the $\mathrm{Ir} 5 \mathrm{~d}$ hole character (with respect to $\mathrm{O}$ in bulk $\mathrm{IrO}_{2}$ ) of the metal atom to which the $\mathrm{O}$ is bound. Oxidation states were changed by varying the termination of a (110) surface of $\mathrm{IrO}_{2}$ from $\mathrm{OH}$ to $\mathrm{O}$, see text for details. In the ball-and-stick model the oxygen, irididium and hydrogen are represented by the red, grey and white balls respectively. Structures: 1. $\mathrm{BrOH} \Sigma \mathrm{CusOH}(110), \mu_{2}-\mathrm{OH}$. 2. $\mathrm{BrOH} \Sigma$ $\mathrm{CusOH}(110), \mu_{1}-\mathrm{OH}$. 3. $\mathrm{IrO}_{2}, \mu_{3}-\mathrm{O}$. 4. $\mathrm{BrO} \Sigma \mathrm{CusOH}(110), \mu_{1}-\mathrm{OH}$. 5. Br-O $\Sigma$ empty Cus (110), $\mu_{2}-\mathrm{O}$. 6. BrO $\Sigma$ CusO (110), $\mu_{2}$ O. 7. BrO $\Sigma$ $\mathrm{CusOH}$ (110), $\mu_{1}-\mathrm{OH}$. 8. empty $\mathrm{Br} \Sigma \mathrm{CusO}$ (110), $\mu_{1} \mathrm{O}$. 9. $\mathrm{BrO} \Sigma \mathrm{CusO}$ (110), $\mu_{1} \mathrm{O}$. larger for the amorphous iridium oxide than for the rutile type [41]. Similar trends were revealed under in situ characterization of iridium electrodes $[42,43]$ and in the ex situ characterization shown in figure 2E. Assuming the near surface region of the reference samples used as fingerprints is not significantly different than the bulk, the broader Ir $4 \mathrm{f}$ (collected at $900 \mathrm{eV} \mathrm{KE}$ ) line shape for the amorphous iridium shows the same trend for the formation of $5 \mathrm{~d}$ holes. The $\mathrm{O} \mathrm{K}$-edge spectra of the two different oxides are shown in Figure 3D. The two sharp features at ca. 529-530 eV and $534 \mathrm{eV}$ are related to the electron transition from the occupied $\mathrm{O} 1 \mathrm{~s}$ core level to the unoccupied $\mathrm{O} 2 \mathrm{p}$ orbitals hybridized 
with the Ir $5 \mathrm{~d}$ orbitals of the Ir, whereas the broader feature at higher excitation energies is due to the excitation of core electrons into the hybridized O 2p-Ir 6sp states [40]. The link between holes on Ir $5 \mathrm{~d}$ and O $2 p$ can be seen by way of DFT calculations. Figure 4, for instance, shows how the amount of hole character of Ir and the surface $\mathrm{O}(\mathrm{H})$ to which it is bound depending on the oxidation state of a rutile-type $\mathrm{IrO}_{2}$ structure. These charges were obtained for a rutile-type (110) surface with various surface terminations, $\mathrm{OH}$ on the bridge and coordinatively unsaturated sites (CUS), $\mathrm{O}$ on the bridge and $\mathrm{OH}$ on the CUS sites, $\mathrm{O}$ on the bridge and CUS sites, and an empty bridge or empty CUS site. In each case the change in hole character ( $\Delta \mathrm{d}$ - and $\Delta \mathrm{p}$-holes) is defined relative to $\mathrm{O} / \mathrm{Ir}$ in bulk rutile-type $\mathrm{IrO}_{2}$ such that a positive number indicates an increase in hole character relative to the bulk oxide. Inspection of the figure reveals that as the metal site is oxidized, eliminating $\mathrm{H}$ terminations, the number $\mathrm{O} 2 \mathrm{p}$ holes on the $\mathrm{O}$ bound to that site also increase in almost linearly fashion. Interestingly, when the number of holes introduced becomes large oxygen acquires more hole density than Ir whereas for a small number of holes the character is shared equally between $\mathrm{Ir}$ and $\mathrm{O}$. The $\mathrm{O}$ in these latter cases is the electrophilic oxygen species appearing at $529 \mathrm{eV}$ in the $\mathrm{O} \mathrm{K}$-edge $[39,44]$. Thus, oxidation of Ir past the formal IV+ state in rutile-type $\mathrm{IrO}_{2}$ leads to the formation of electron deficient oxygen. Due to the O2p-Ir5d hybridization, the formation of electrons/holes in the Ir $5 \mathrm{~d}$ leads to the formation of new oxygen species as seen in the pre-edge $(\sim 529 \mathrm{eV})$ of the $\mathrm{O}$ K-edge XANES spectrum. The electron deficiency generated by the formation of $5 \mathrm{~d}$ holes and the steric factor due to the presence of the other oxygen ligands around the Ir center are considered here as key factors in the formation of the electrophilic oxygen species previously observed, namely the formally $\mathrm{O}^{\mathrm{I}-}$ species [34], which could explain the peculiar reactivity of Ir during the OER. This high degree of covalency leads to the sharing of electron-holes between $\mathrm{O} 2 \mathrm{p}$ and $\mathrm{Ir} 5 \mathrm{~d}$ seen by comparing the $\mathrm{O} \mathrm{K}$-edge and the Ir L-edge spectra. Within this picture, when the number of Ir $5 \mathrm{~d}$ holes increases the strong hybridization with $\mathrm{O} 2 \mathrm{p}$ orbitals leads to a sharing of holes as shown schematically in figure $5 \mathrm{~A}$, in yellow. Therefore the feature shown in the $\mathrm{O} \mathrm{K}$-edge at $529 \mathrm{eV}$ is associated with the amount of hole character introduced to oxygen as iridium is oxidized during the OER. These holes have two roles in OER: i) as hole on the $\mathrm{IrO}_{\mathrm{x}}$ metal site that produces the key energetically non-favorable intermediate metaloxo/oxyl species and, ii) the formation of the electrophilic $\mathrm{O}^{\mathrm{I}-}$ oxygen which are susceptible to nucleophilic attack.

Based on the electronic structure revealed by the X-ray spectroscopies used in this work and the fact that metal-oxo-oxyl [45] sites are proposed to be involved in the O-O bond formation leading to the oxygen evolution [46], two different mechanisms are proposed in literature [47]: in the acid base mechanism, the nucleophilic oxygen atom of water or hydroxide attacks the electrophilic oxygen of the metal-oxo-oxyl site and as consequence molecular oxygen evolves; otherwise, in the radical coupling mechanism, two adjacent metal-oxo-oxyl species with radical character couple and evolves molecular oxygen [48]. The acid-base mechanism requires electrophilic oxygen atoms on the surface while radical coupling requires oxygen atoms with radical character, both of which are electron deficient. In latter case, the oxygen radicals must be sufficiently close to each other to form an O-O bond. Hence, electronic, kinetic and steric factors 
will favor one or the other mechanism. The electronic factor is dominated by the electron density at the metal center and the surrounding ligand field, both controlling the metal-oxo-oxyl bond strength. The occupancy of the metal $\pi / \pi^{*}$ bonding/antibonding states determine the nature of the oxo-oxyl-sites. In the case of empty $\mathrm{d}$ orbitals, the metal is able to accept the $\mathrm{p}_{\mathrm{x}}$ and $\mathrm{p}_{\mathrm{y}}$ electron pairs of the oxo-oxyl ligand forming the bond and making the atomic ensemble extremely electrophilic. The metaloxide center can therefore act as a Lewis acid site and become susceptible to nucleophilic attack from adsorbed water. A situation with high hole density on Ir would therefore favor the acid-base mechanism. On the other hand, with increasing of the d orbitals' occupancy, the metal center increasingly acts as an electron donor, resulting in a lower formal Ir$\mathrm{O}$ bond order. The most active amorphous catalyst in this study also exhibited the highest hole density on Ir, as shown by the Ir L3-edge measurements and the cyclic voltammetry. This suggests that the most suitable mechanism describing the intermediate step of $\mathrm{O}-\mathrm{O}$ bond formation preceding its evolution into molecular oxygen is the nucleophilic attack of water molecules on the metal-oxo/oxyl sites due to the existence in both $\mathrm{O}$

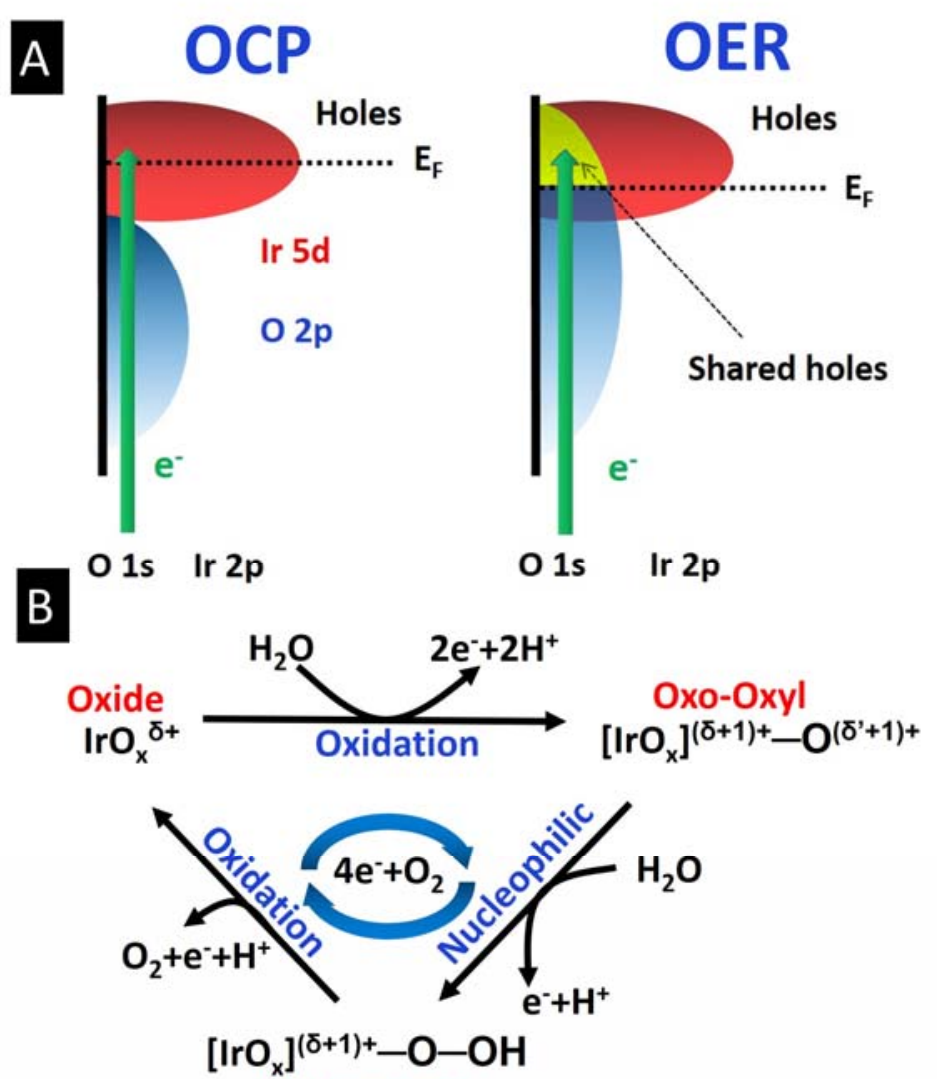

Hydroperoxy

Figure 5: (A) Schematic of the O K-edge and Ir L-edge of the hybridized overlapping O $2 p$ with Ir $5 d$ states yielding the share of holes between both states, at open circuit potential (OCP) and during oxygen evolution reaction (OER). (B)Proposed reaction path following the activation of highly stable metal-oxide to form metal-oxo-oxyl which is further nucleophilic attacked to yield hydroperoxy. This hydropereoxy yields by oxidation the formation of dioxygen.

$2 \mathrm{p}$ and Ir $5 \mathrm{~d}$ and not so likely only in Ir $5 \mathrm{~d}$ (oxo bond) or O $2 \mathrm{p}$ (oxyl bond). Thus, the holes on Ir $5 \mathrm{~d}$ drive the formation of electrochemical active $\mathrm{O}^{\mathrm{I}-}$ which was identified as a key factor for catalytic reactivity of iridium oxides, as well as for the reaction path of the OER. Additional hole character on Ir 5d lowers the OER overpotential due to an interaction with the O 2p orbitals, which finally enables the formation of a metal-oxo-oxyl intermediate $\mathrm{O}^{\mathrm{I}-}$ species active in OER.

Consequently, the OER on an $\mathrm{IrO}_{x}$ catalyst can be tentatively described by its analogy with the oxo-bridge in the photosystem II, where the oxidation of water to molecular oxygen involves 
the formation of an oxo-oxyl species [49,50]. This active site undergoes nucleophilic attack by water and forms an O-O bond (as shown in figure 5B). Similarly, the catalytic oxidation of water on $\mathrm{IrO}_{\mathrm{x}}$, happens via an electron deficient oxyl-complex, which is the active species for the formation of the O-O bond as indicated by the formation of shared holes between Ir $5 \mathrm{~d}$ and O $2 \mathrm{p}$. The oxidation of the resulting hydroperoxy $[51,52]$ intermediate yields the final product dioxygen, and the catalyst recovers by coordination with $\mathrm{H}_{2} \mathrm{O}$. We postulate that the overall reaction key is the formation of a hydroperoxy bond, through the nucleophilic attack of an oxyl ligand by water or $\mathrm{OH}$. The proposed mechanism is illustrated in Figure 5B where one cycle fulfills the overall OER reaction formula $\mathrm{IrO}_{x}+\mathrm{H}_{2} \mathrm{O} \rightarrow \mathrm{IrO}_{\mathrm{x}}+\mathrm{O}_{2}+4 \mathrm{H}^{+}+4 \mathrm{e}^{-}$, with the exact iridium oxidation state remaining as major subject of further investigations requiring accurate preparation of fingerprint samples. The iridium-oxo-oxyl (namely before $\mathrm{O}^{-}$[29]) species appear to be the key intermediate, which can activate oxygen, with its reactivity determined by the metal ligand interaction. Higher potentials form holes in the Ir $5 \mathrm{~d}$ level and the hybridization with the $\mathrm{O} 2 \mathrm{p}$ orbitals leads to an electron deficient oxygen species with electron-holes shared between $\mathrm{O}$ and $\mathrm{Ir}$, which is then active in OER due to its double character in the formation of metal-oxo-oxyl and nucleophilic $\mathrm{O}^{-}$species yielding hydroperoxy which further oxidize to form dioxygen.

\section{Conclusions}

In this work, the electronic structure of a free standing graphene electrode decorated with Ir NPs for OER in acidic environment was conducted. In situ X-ray spectroscopy revealed that the OER on the surface of the $\mathrm{IrO}_{\mathrm{x}} \mathrm{NPs}$ is similar to the oxo-oxyl-bridge formation in the photosystem II. The reaction is driven by the formation of shared electron-holes in the $\mathrm{O} 2 \mathrm{p}$ and $\mathrm{Ir} 5 \mathrm{~d}$ which activate oxygen by making it electron-deficient. Thus, the oxidation of water into dioxygen involves the formation of an oxo-oxyl-metal-complex and the oxygen in this complex is susceptible to nucleophilic attack by water or $\mathrm{OH}$, which results in hydroperoxy bond formation. The hydroperoxy species is then finally transformed into molecular dioxygen. The proposed reaction pathway was developed around the formation of the O-O bond as the key step. Consequently, the formation of shared holes in the $\operatorname{Ir} 5 \mathrm{~d}$ and $\mathrm{O} 2 \mathrm{p}$ is a catalytic activity descriptor and can be used to synthesize more active materials for the OER rather than absorption energy.

\section{Acknowledgements}

The authors acknowledge BESSY II/ HZB for allocating beamtime within the project number $16103418 \mathrm{CR}$. This work was further supported by the Ministry of Education and Science of the Russian Federation (RFMEFI61614X0007) and the Bundesministerium für Bildung und Forschung (05K14EWA) through the joint Russian-German research project "SYnchrotron and NEutron STudies for Energy Storage" (SYNESTESia).". We thank DAAD for financial support in the framework of Taiwanese-German collaboration (project ID 57218279 and 57392335). C.H.C. acknowledges financial support from projects 106-2112-M-032-003. S.H. acknowledges funding from EPSRC (EP/K016636/1) and R.W. acknowledges EPSRC Doctoral Training Award (EP/M506485/1). 


\section{References}

[1] J. H. Seinfeld, S. N. Pandis, Atmospheric chemistry and physics: from air pollution to climate change, John Wiley \& Sons, 2011.

[2] A. J. McMichael,R. E. Woodruff, S. Hales, The Lancet, 367 (2006) 859.

[3] T. L. Root, J. T. Price, K. R. Hall, S. H. Schneider, C. Rosenzweig, J. A. Pounds, Nature 421(2003) 57.

[4] F. Caiazzo, A. Ashok, I. A. Waitz, S. H. Yim, S. R. Barrett, Atmospheric Environment,79 (2013) 198.

[5]http:/www.who.int/mediacentre/news/releases/2016/deaths-attibutable-to-unhealthyenvironments/en/

[6] J. Chow, J. R. Kopp, P. R. Portney, Science 302 (2003) 1528.

[7] S. Chu, A. Majumdar, Nature 488(2012) 294.

[8] R. Schlögl, ChemSusChem 3(2010) 209.

[9] J. A. Turner, Science 305 (2004) 972.

[10] M. G. Walter, E. L. Warren, J. R. McKone, S. W. Boettcher, Q. Mi, E. A. Santori, N. S. Lewis, Chem. Rev. 110 (2010) 6446.

[11] K. Gong, F. Du, Z. Xia, M. Durstock, L. Dai, Science 323(2009) 760.

12 Y. Gorlin, T. F. Jaramillo, JACS 132 (2010) 13612.

[13] Y. Lee, J. Suntivich, K. J. May, E. E. Perry, Y. Shao-Horn, J. Phys. Chem. Lett. 3 (2012) 399.

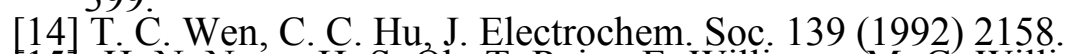

[15] H. N. Nong, H. S. Oh, T. Reier, E. Willinger, M. G. Willinger, V. Petkov, D. Teschner, P. Strasser, Angew. Int. Ed. 54 (2015) 2975.

[16] T. Reier, M. Oezaslan, P. Strasser, , ACS Catalysis 2 (2012) 1765.

[17] A. K. Geim, K. S. Novoselov, Nat. Mat. 6 (2007) 183.

[18] A. H. Castro Neto, F. Guinea, N. M. R. Peres, K. S. Novoselov, A. K. Geim, Rev. Mod. Phys. 81 (2009) 109.

[19] A. K. Geim, Science 324 (2009) 1530.

[20] Y. Zhu, S. Murali, W. Cai, X. Li, J.W. Suk, J.R. Potts, R.S. Ruoff, Adv. Mat 22 (2010) 3906.

[21] J. J. Velasco-Velez, C. H. Chuang, H. L. Han, I. Martin-Fernandez, C. Martinez, W. F. Pong, Y. R. Shen, F. Wang, Y. Zhang, J. Guo, M. Salmeron, JES 160 (2013) C445.

[22] J. J. Velasco-Vélez, V. Pfeifer, M. Hävecker, R. Wang, A. Centeno, A. Zurutuza, g: AlgaraSiller, E. Stotz, K. Skorupska, D. Teschner, P. Kube, P. Braeuninger-Weimer, S. Hofmann, R. Schlögl, A. Knop-Gericke, Rev. Sci. Inst. 87 (2016) 053121.

[23] A. Kolmakov, D. A. Dikin, L. J. Cote, J. Huang, M. K. Abyaneh, M. Amati, M. Kiskinova, Nature nanotechnology 6 (2010) 651.

[24] J. J. Velasco-Velez, V. Pfeifer, V., M. Hävecker, R. S. Weatherup, R. Arrigo, C. H. Chuang, E. Stozt, G. Weinberg, M. Salmeron, R. Schlögl, A. Knop-Gericke, Ang. Chem. Int.l Ed. 54 (2015) 14554.

[25] https://www.helmholtz-

berlin.de/pubbin/igama_output?modus=einzel\&sprache=en\&gid=1671

[26] http://efd.nsrrc.org.tw/EFD.php?num=233

[27] J. J. Velasco-Velez, C. H. Wu, B. Y. Wang, Y. Sun, Y. Zhang, J. H. Guo, M. Salmeron, J. Phys. Chem. C 118 (2014) 25456.

[28] P. Lettenmeier, L. Wang, U. Golla-Schindler, P. Gazdzicki, N. A. Cañas, M. Handl, K. A. Friedrich, Ang. Chem. 128 (2016) 752. 
[29] V. Pfeifer, T. E. Jones, J. J. Velasco Vélez, C. Massué, R. Arrigo, D. Teschner, F. Girsdies, M. Scherzer, M. T. Greinerr, J. Allan, M. Hashagen, G. Weinberg, S. Piccinin, M. Hävecker, A. Knop-Gericke, R. Schlögl, Surface and Interface Analysis 48 (2015) 261.

[30] P. Giannozzi, S. Baroni, N. Bonini, M. Calandra, R. Car, C. Cavazzoni, D. Ceresoli, G. L. Chiarotti, M. Cococcioni, I. Dabo, A. D. Corso, S. d. Gironcoli, S. Fabris, G. Fratesi, R. Gebauer, U. Gerstmann, C. Gougoussis, A. Kokalj, M. Lazzeri, L. Martin-Samos, N. Marzari, F. Mauri, R. Mazzarello, S. Paolini, A. Pasquarello, L. Paulatto, C. Sbraccia, S. Scandolo, G. Sclauzero, A. P. Seitsonen, A. Smogunov, P. Umari, R. M. Wentzcovitch, J.Phys.: Cond. Matter 21 (2009) 395502. [31] J. P. Perdew, K. Burke, M. Ernzerhof, Phys. Rev. Lett. 78 (1997) 1396.

[32] A. Dal Corso, Comp. Mat. Sci. 95 (2014) 337.

[33] N. Marzari, D. Vanderbilt, A. De Vita, M. C. Payne, Phys. Rev. Lett. 82 (1999) 3296.

[34] S. Song, H. Zhang, X. Ma, Z. Shao, R. T. Baker, B. Yi, Int. J. Hyd. Ener, 33 (2008) 4955.

[35] P. Lettenmeier, L. Wang, U. Golla-Schindler, P. Gazdzicki, N. Cañas, M. Handl, R. Hiesgen, S. S. Hosseiny, A. S. Gago, K. A: Friedrich, Ang. Chem. Int. Ed. 128 (2016) 752.

[36] E. J. Frazer, R. Woods, J. Elec. Chem. Interf. Electrochem. 102 (1978) 127.

[37] H. G. Sanchez Casalongue, M. L. Ng, S. Kaya, D. Friebel, H. Ogasawara, A. Nilsson, Ang. Chem. Int. Ed. 53 (2014) 7169.

[38] V. Pfeifer, T. E. Jones, J. J. Velasco-Vélez, C. Massué, M. T. Greiner, R. Arrigo, D. Teschner, F. Girsdies, M. Scherzer, M. T. Greinerr, J. Allan, M. Hashagen, G. Weinberg, S. Piccinin, M. Hävecker, A. Knop-Gericke, R. Schlögl, Phys. Chem. Chem. Phys. 18 (2016) 2292.

[39] V. Pfeifer, T. E. Jones, J. J. Velasco-Vélez, R. Arrigo, S. Piccinin, M. Hävecker, A. KnopGericke, R. Schlögl, Chemical Science 8 (2017) 2143.

[40] H. M. Tsai, P. D. Babu, C. W. Pao, J. W. Chiou, J. C. Jan, K. P Krishna Kumar, F. Z.Chien, W. F. Pong, App.Phys. Lett. 90 (2007) 042108.

[41] J. P. Clancy, N. Chen, C. Y. Kim, W. F. Chen, K. W. Plumb, B. C. Jeon, B. T. W: Noh, Y. J. Kim, Phys. Rev. B, 86 (2012), 195131.

[42] Y. Mo, I. C. Stefan, W. B. Cai, J. Dong, P. Carey, D. A. Scherson, J. Phys. Chem. B, 106 (2002) 3681 .

[43] A. Minguzzi, C. Locatelli, O. Lugaresi, E. Achilli, G. Cappelletti, M. Scavini, M. Coduri, P.Masala, B. Sacchi, A. Vertova, P. Ghigna, S. Rondinini, ACS Catalysis, 5 (2015) 5104.

[44] V. Pfeifer, T. E. Jones, C. Massué, J. J. Velasco-Vélez, C. Massué, R. Arrigo, M. Scherzer, S. Piccinin, M. Hävecker, A. Knop-Gericke, R. Schlögl, Chemical Science, 7 (2016) 6791.

[45] P. E. Siegbahn, Proc. Nat. Acad. Sci. (2017) 201617843.

[46] J. D. Blakemore, N. D. Schley, D. Balcells, J. F. Hull, G. W. Olack, C. D. Incarvito, O. Eisenstein, G. W.Brudvig, R. H. Crabtree, JACS 132 (2010) 16017.

[47] S. Kundu, M. Schwalbe, K. Ray,BioInorg. React Mech 8 (2012) 41.

[48] T. A. Betley, Q. Wu, T. Van Voorhis, D. G. Nocera, Inorg. Chem. 47 (2008) 1849.

[49] Y. Umena, K. Kawakami, J. R. Shen, N. Kamiya, Nature 473 (2011) 55.

[50] T. Lohmiller, V. Krewald, A. Sedoud, A. W. Rutherford, F. Neese, W. Lubitz, D. A. Pantazis, N. Cox, JACS 139 (2017) 14412.

[51] B. S. Yeo, S. L. Klaus, P. N. Ross, R. A. Mathies, A.T. Bell, ChemPhysChem, 11 (2010) 1854. 
[52] J. A. Gauthier, C. F. Dickens, L. D. Chen, A. D. Doyle, J. K. Norskov, J. oPhys. Chem. C. 121 (2017) 11455. 